\title{
"Evaluation And Correlation of Insulin Resistance And Lipid Profile In Normal Pregnancy And Preeclampsia"
}

\author{
Partiksha ${ }^{1}$, Ruby Bhatia ${ }^{2}$,Chittranjan Vij ${ }^{1}$, Gurdeep Bedi ${ }^{1}$, \\ Paramjit Kaur $^{2}$ \\ ${ }^{I}$ Department of Biochemistry and \\ ${ }^{2}$ Department of Obstetrics \& Gynecology, Govt. Medical College, Patiala, Punjab
}

\section{Corresponding author information}

Dr Ruby Bhatia,

Associate Professor,

Department of Obstetrics and Gynecology,

Government medical college and hospital, Patiala

\begin{abstract}
Background: Preeclampsia syndrome is clinical spectrum of worsening disease with attenuated manifestations to cataclysmic deterioration, Life threatening for both mother and fetus. It affects 5-10\% of all pregnancies \& forms deadly triad with haemorrhage and infection being a direct cause of maternal mortality. Preeclampsia is associated with hyper insulinemia, increased insulin resistance which induces hypertriglyceridemia, endothelial dysfunction. It may lead to preeclampsia in genetically predisposed pregnant women. Association of high serum lipids with gestational protinuric hyerptension is highly suggestive of role for lipid profile analysis as diagnostic tool for preeclampisa.

Aims \& Objective: To evaluate and correlate fasting plasma insulin levels, insulin resistance and lipid profile in preeclampsia and normal pregnancy in $\geq 20$ wks gestation.

Material \& methods: This is prospective observational study undertaken for one year on 40 pregnant women with preeclampsia and 25 normal pregnant women in tertiary care hospital in North India. Fasting plasma insulin levels, insulin resistance and lipid profile were evaluated in all 65 pregnant women in study and control group.

Results: Mean age $26 . \pm 4.48$ years, $25.0 \pm 2.79$ years, mean period of gestation $32.38 \pm 2.53$ wks, $29.48 \pm 2.50$ weeks in study \& control group respectively were comparable. $52 \%$ patients in both the groups were primigravida. Mean fasting plasma insulin levels in study group i.e. $53.3 \mu \mathrm{IU} / \mathrm{ml}$ was significantly higher than, $16.35 \mu I U / m l$ in control group. Insulin resistance (HOMA IR index) in preeclampsia was 10.33, significantly high compared to 3.04 in normotensive pregnant women. Lipid profile- serum cholesterol, triglycerides, $H D L$, $L D L, V L D L$ were significantly raised in preeclampsia compared to control group.

Conclusion: Highly significant increase in fasting plasma insulin levels, insulin resistance and lipid profile compared to normotensive pregnant females is a diagnostic tool for early diagnosis and management of preeclampsia - step towards reducing maternal mortality and adverse fetal outcome.
\end{abstract}

Keywords: Preeclampsia, Insulin Resistance, Plasma Insulin Levels, Lipid profile, Pregnant.

\section{Introduction}

Hypertensive disorders in pregnancy form a deadly triad with hemorrhage \& infection, being a direct cause of maternal mortality worldwide. It complicates $5-10 \%$ of all pregnancies. ${ }^{[1]}$ Of these hypertensive disorders, preeclampsia syndrome is the most ominous. Preeclampsia syndrome is clinical spectrum of worsening disease with attenuated manifestation to cataclysmic deterioration, life threatening for both mother \& fetus. It also causes one tenth of maternal deaths in Asia and Africa and one Quarter of maternal deaths in Latin America. ${ }^{[2]}$ Preeclampsia syndrome is a multiorgan dysfunction characterized by Blood pressure of $\geq 140 / 90$ $\mathrm{mm} \mathrm{Hg}$ and proteinuria after mid-gestation i.e. 20 weeks of pregnancy. Multiorgan involvement may include thrombocytopenia, renal dysfunction, hepatocellular necrosis, central nervous system perturbations, or pulmonary edema. It is leading cause of fetal growth restriction, intra uterine fetal demise and preterm birth. ${ }^{[3]}$ Pregnancy is characterized by a series of metabolic changes that promote adipose tissue accretion in early gestation followed by insulin resistance and facilitated lipolysis in late pregnancy. In early pregnancy insulin secretion increases while insulin sensitivity is unchanged, decreased or may even increase. There is $50 \%$ decrease in insulin mediated glucose disposal \& 200-250\% increase in insulin secretion to maintain Euglycemia in mother. ${ }^{[4]}$ 
The insulin resistance syndrome provides a link between pregnancy induced hypertension and its risk factors and sequalae in both pregnancy \& later life. ${ }^{[5]}$ Preeclampsia and Gestational hypertension are associated with exaggerated hyperinsulnemia relative to normal pregnancy. Hyperinsulinemia in pregnancy predisposes to hypertension by increased sodium reabsorption and stimulation of sympathetic nervous system. Insulin resistance and / or associated hyperglycemia may impair endothelial function. ${ }^{[6]}$ Many of the features of insulin resistance i.e. Hypertension, Hyperinsulinemia, Glucose intolerance, obesity, lipid abnormalities, increased leptin, increased TNFa, increased TPA and PA1-I, Elevated Testosterone and reduced SHBG are associated with preeclampsia. ${ }^{[5]}$ Increased insulin resistance activates sympathetic nervous system leading to an increased expression of receptors for endothelin which results in increased blood pressure. Hyperinsulinemia induces hypertriglyceridemia, endothelial dysfunction and reduction in prostacyclin production. Insulin resistance may not be the cause of preeclampsia but is one of the pathogenic factors in genetically predisposed women. ${ }^{[7]}$ Abnormal lipid metabolism seems important in pathogenesis of preeclampsia. Association of serum lipids with gestational proteinuric hypertension is highly suggestive of role for lipid profile analysis as diagnostic tool. ${ }^{[8]}$ It has direct effect on endothelial dysfunction. Hypertension in pregnancy is supposed to be due to vasospastic phenomenon in kidney, uterus, placenta and brain. Altered lipid synthesis leads to decrease in $\mathrm{PGI}_{2}$; $\mathrm{TXA}_{2}$ ratioan important pathway in pathogenesis of preeclampsia. Increased triglycerides in preeclampsia may be deposited in uterine spiral arteries leading to endothelial dysfunction through generation of small dense LDL. ${ }^{[9]}$ In addition hypertriglyceridemia is associated with hypercoagulability. ${ }^{[10]}$

\section{Aims \& Objectives}

- To evaluate insulin resistance and lipid profile (Serum cholesterol, Serum Triglycerides, HDL, LDL, VLDL) in preeclampsia and normal pregnancy in $\geq 20$ weeks gestation.

- To observe correlation of insulin resistance and lipid profile with preeclampsia and normal pregnancy in $\geq 20$ weeks gestation.

\section{Material \& Methods}

- The present study was conducted in departments of Biochemistry and Obstetrics and Gynecology, Govt. Medical College, Patiala, Punjab w.e.f. June 2012 to May 2013 on 65 pregnant females. Patients were divided into study group and control group.

- Study Group: 40 pregnant patients with pre-eclampsia at $\geq 20$ weeks gestation. Study group was further divided into: non-severe preeclampsia and severe pre-eclampsia.

- Control Group: 25 pregnant normotensive women at $\geq 20$ weeks gestation. All patients were subjected to routine hematological and biochemical investigation of pregnancy followed by special investigations i.e. fasting plasma insulin levels and lipid profile (serum cholesterol, triglycerides, HDL, LDL \& VLDL). Evaluation of insulin resistance was done using homeostasis model assessment HOMA.

\section{Fasting plasma glucose mmol / L $\times$ Fasting Plasma Insulin $\mu \mathrm{mol} / \mathrm{L}$$$
22.5
$$

Data was compiled and analysed for statistical significance.

\section{Results}

Mean age in the study group $26.6 \pm 4.48$ years and $25.0 \pm 2.79$ years in control group was comparable. 52.5 patients in study group and $52 \%$ in control group were primigravida. Mean period of gestation was $33.38 \pm$ 2.53 weeks in study group and $29.48 \pm 2.50$ weeks in control group (Table 1 ).

- A total of 23 cases $(57.5 \%)$ in study group had severe preeclampsia while $17(42.5 \%)$ had non severe preeclampsia (Table 2a), Mean systolic blood pressure in study group was $156.00 \pm 14.10 \mathrm{mmHg}$ against $114.40 \mathrm{mmHg}$ in control group. Mean diastolic blood pressure was $105.25 \mathrm{mmHg}$ and $76.00 \mathrm{mmHg}$ in study and control group. The difference in two groups was statistically highly significant $\mathrm{p}<0.001$ (Table 2b)

- Serum creatinine, uric acid and LFT were significantly higher and platelet count lower in study group (Table 3).

- Mean fasting plasma insulin levels in study group was $53.31 \mu \mathrm{IU} / \mathrm{ml}$ compared to $16.35 \mu \mathrm{IU} / \mathrm{ml}$ in control group, difference being statistically highly significant $(\mathrm{p}<0.001)$. Mean fasting plasma insulin level in severe preeclampsia was $72.33 \mu \mathrm{IU} / \mathrm{ml}$ compared to $39.25 \pm 12.22 \mu \mathrm{IU} / \mathrm{ml}$ in Non severe preeclampsia. However hemoglobin and fasting plasma glucose levels were comparable in both the groups (Table 4).

- Homa IR index in study group was 10.33 and 3.04 in control group, difference being statistically highly significant $(\mathrm{p}<0.001)$, Homa IR Index in severe preeclampsia was $13.83 \pm 3.23$ and non-severe preeclampsia 7.74 \pm 2.37 , significantly raised compared to control group (Table 5). 
- Lipid profile (serum cholesterol, triglyceride, HDL, LDL, VLDL) were significantly raised in non severe and severe preeclampsia compared to control group ( $\mathrm{p}$ value $<0.001$ ). With severity of preeclampsia, total cholesterol also rises, may be result of oxidative stress contributing to atherogenesis and pathogenesis of preeclampsia. A positive correlation was also found between serum triglycerides and LDL with severity of preeclampsia, $\mathrm{p}<0.001$ (Table 7).

\section{Discussion}

Mean age of preeclampsia in our study group $26.60 \pm 4.48$ years was comparable with Pashupathy et al 2009 and Islam et al 2010 i.e. 27 years and 24 years respectively. ${ }^{[11,12]} 52.5 \%$ women with preeclampsia in our study group were primigravida while Dhananjaya 2011 reported $64 \%$ women with preeclampsia to be primigravida in his study. ${ }^{13]}$ Mean period of gestation in study group was $32.38 \pm 2.53$ weeks and $29.48 \pm 2.50$ weeks in control group respectively while Pashupathy et al 2009 in his study reported 34.3 weeks and 35 weeks respectively. ${ }^{[11]}$ Plasma insulin levels in our study group were very high $53.30 \pm 22.52$ compared to $16.35 \pm 5.72$ $\mu \mathrm{IU} / \mathrm{ml}$ in control group. Difference being statistically highly significant. Plasma insulin levels were found to be higher in the studies done by Xu et al, 2000, Paradisi et al 2006 and Girouard et al 2007 and Hauth et al 2011 (Table 5c). ${ }^{[14,15,16,17]}$ Mean fasting plasma insulin levels in severe preeclampsia were significantly higher $72.33 \pm$ $19.16 \mu \mathrm{IU} / \mathrm{ml}$ than nonsevere preeclampsia $39.25 \pm 12.22 \mu \mathrm{IU} / \mathrm{ml}]$. Exaggerated hyperinsulinemia relative to normal pregnancy is well described in women with established preeclampsia or gestational hypertension being consistent with hypothesis that insulin resistance may play a role in PIH pathogenesis. Mean value of HOMA IR Index in preeclampsia was higher (10.33) than control group (3.04) the difference was statistically highly significant ( $\mathrm{p}$ value $<0.001$ ) Mean HOMA IR, Index in severe preeclampsia was 13.83 compared to 7.74 in non severe preeclampsia difference being highly significant $(\mathrm{p}<0.001)$. Kocigyit et al (2004) also reported similar findings. ${ }^{[18]}$ Serum cholesterol levels and lipid profile were significantly higher in severe and non severe preeclampsia compared to normal pregnant women in our study. Similar findings were observed by Pashupathi et al 2009. ${ }^{[11]}$ Physiological insulin resistance is exaggerated in preeclampsia. Gestational insulin resistance may accentuate suppression of lipoprotein lipase activity and increase mobilization of free fatty acids from visceral adipocytes, explaining hypercholestremia in preeclampsia. ${ }^{[19]}$

There was highly significant correlation of fasting plasma insulin, HOMA-IR index with serum cholesterol, serum triglycerides, LDL and VLDL levels, all being significantly raised in preeclampsia. Similar observations were made by Asemi et al 2013. ${ }^{[20]}$

\section{Conclusion}

Patients with preeclampsia had significant increase in fasting plasma insulin levels, insulin resistance and significant increase in lipid profile levels (serum cholesterol triglycerides, HDL, LDL and VLDL) compared to normotensive pregnant females. Increased fasting insulin levels, Increased insulin resistance as well as raised lipid profile parameters are diagnostic and prognostic tool for early diagnosis and management of preeclampsia there by reducing maternal morbidity and mortality and adverse fetal outcome. Further, studies on larger population may be a step towards achievement of sustainable development goal-3 in decreasing maternal mortality to 70 per 100,000 live births by 2030 .

\section{Bibliography}

[1]. Cunningham FG, Leveno KJ, Bloom SL, Hauth JC, Rouse DJ, Spong CY, Williams Obstetrics -24th Edition Hypertensive Disorders: Chapter 40 pg.728-779.

[2]. 2 WHO Recommendations for prevention and treatment of preeclampsia and eclampsia WHO/RHR/14.17 2013.

[3]. Khan KS, Wojdyla D, Say L, Gulmezogler AM, VanLooket P, WHO Analysis of causes of maternal death : a systematic review, Lancet 2006; 367 (9516) : 1066-74.

[4]. Cutalano PM, Huston L, A mini SB, Kalhan SC. Longitudinal changes in glucose metabolism during pregnancy in obese women with normal glucose tolerance and gestational diabetes mellitus. Am J Obstet Gynecol 1999, 180(4) : 903-16.

[5]. Seely EW, Solomon CG. Insulin resistance and its potential role in pregnancy induced hypertension. J Clin Endocrinol Metab, $2003 ; 88(6): 2393-8$.

[6]. Calles - EScandon J, Cipolla M. Diabetes and Endothelial dysfunction : a clinical perspective, Endocr Rev. 2001; 22(1) : $36-52$.

[7]. Kaaja R. Insulin resistence syndrome in preeclampsia : Semen Reprod Endocrinol 1998; 16(1) : 41-6.

[8]. Dutta DC Hypertensive disorders in pregnancy. In : Konor HL, editor. Text book of obstetrics Kolkata : New Central Book Agency $2001 ; 5: 234-55$.

[9]. Sattar N, Greer L, Louden J. Lipoprotein sub fraction changes in normal pregnancy; threshold effects of plasma triglycerides on appearance of small dense LDL. J Clin Endocrinol Metab 1997; 82 : 2483-91.

[10]. Kokia E, Barkai G, Reichman B, Segal P, Goldman B, Mashiach S. Maternal Serum lipid profile in pregnancies complicated by hypertensive disorders. J Perinat Med 1990, 18(6) : 473-8.

[11]. Pashupathi P, Deepa M, Rani P, Cidhya Sankar KB, Satish Kumar SP, Evaluation of Serum lipids and thyroid harmone changes in non pregnant, pregnant and pre eclampsia women. Thyroid Science 2009; 4(10): CLS1-6.

[12]. Islam NAF, Chowdhry MAR, Kibria GM, Akhter, S. Study of Serum lipid profile in Preeclampsia and Eclampsia. Faridpur Med Coll, J. 2010; 5(2) : 56-59. 
[13]. Dhananjaya BS, Sendil Kumaran D, Venkatesh G, Niravyan M, Shashi Raj HK, Thyroid stimulating harmone level as a possible indicator of preeclampsia Journal of Clinical and Diagnostic Research. 2011; 5(8); 1542-43.

[14]. Xu X, Qiao M, Jiang M. Relationship between insulin resistance and pregnancy induced hypertension. Zhonghua Fu Chan Ke Zazhi 2000; 35(10): 597-9.

[15]. Paradissi G, Biaggi A, Savone R, Lanniello F, Tomel C et al. Cardiovascular risk factors in healthy women with previous gestational hypertension J Clin Endocrinol Metabolism 2006; 91(4) : 1233-8.

[16]. Giroud J, Giguesre Y, Moutquin JM, Forest JC. Previous hypertensive disease of pregnancy associated with markers of insulin resistance. Hypertension. 2007; 49(5) : 1056-62.

[17]. Hauth JC, Clifton RG, Roberts JM, Myatt L, Spongy CY et al. Maternal insulin resistance and preeclampsia. Am J Obstet Gynaecol 2011; 204(4) : 327 e1-6.

[18]. KocYigit Y, Bayhan G, Atamer A, et al. Serum levels of leptin, insulin like growth factor-1 and insulin like growth factor binding protein-3 in women with preeclampsia and their relationship to insulin resistance. Gynaecol Endocrinol. 2004; 18(6) : 341-8.

[19]. Ramsay JE, Jamieson N, Greer IA, Sattar N, Paradoxical elevation in adiponectin concentrations in women with preeclampsia Hypertension2004; 43 : e17.

[20]. Asemi Z, Jazayeri S, Najafi M Samimi M et al. Association between markers of systemic inflammation, oxidative stress, lipid profiles, insulin resistance in pregnant women ARYA Atheroscler. 2013; 9(3) : 172-8.

Table 1: Demographic characteristics

\begin{tabular}{|l|l|l|l|l|}
\hline \multirow{2}{*}{ Age in years } & \multicolumn{2}{|c|}{ Study Group } & \multicolumn{2}{c|}{ Control Group } \\
\cline { 2 - 5 } & No. & \% age & No. & \% age \\
\hline$\leq 20$ & 2 & $5.0 \%$ & 1 & $4 \%$ \\
\hline $21-25$ & 18 & $45.0 \%$ & 14 & $56 \%$ \\
\hline $26-30$ & 12 & $30.0 \%$ & 9 & $36 \%$ \\
\hline $31-35$ & 7 & $17.5 \%$ & 1 & $4 \%$ \\
\hline $36-40$ & 1 & $2.5 \%$ & 0 & $0 \%$ \\
\hline Total & $\mathbf{4 0}$ & $\mathbf{1 0 0 \%}$ & $\mathbf{2 5}$ & $\mathbf{1 0 0 \%}$ \\
\hline Mean Age + SD & $\mathbf{2 6 . 6} \pm \mathbf{4 . 4 8}$ & $\mathbf{2 5 . 0 \pm \mathbf { 2 . 7 9 }}$ \\
\hline
\end{tabular}

\begin{tabular}{|c|c|c|c|c|}
\hline \multirow{2}{*}{ Gravida } & \multicolumn{3}{|c|}{ Study Group } & \multicolumn{2}{c|}{ Control Group } \\
\cline { 2 - 5 } & No. & \% age & No. & \% age \\
\hline 1 & 21 & $52.5 \%$ & 13 & $52 \%$ \\
\hline 2 & 7 & $17.5 \%$ & 9 & $36 \%$ \\
\hline 3 & 6 & $15.0 \%$ & 3 & $12 \%$ \\
\hline$>3$ & 6 & $15.0 \%$ & 0 & $0 \%$ \\
\hline Total & 40 & $100 \%$ & 25 & $100 \%$ \\
\hline
\end{tabular}

\begin{tabular}{|l|l|l|l|l|}
\hline \multirow{2}{*}{ POG in weeks } & \multicolumn{1}{|c|}{ Study Group } & \multicolumn{2}{c|}{ Control Group } \\
\cline { 2 - 5 } & No. & \% age & No. & \% age \\
\hline $20-25$ & 0 & $0 \%$ & 1 & $4 \%$ \\
\hline $26-30$ & 13 & $32.5 \%$ & 16 & $64 \%$ \\
\hline $31-35$ & 22 & $55.0 \%$ & 8 & $32 \%$ \\
\hline$>35$ & 2 & $12.5 \%$ & 0 & $0 \%$ \\
\hline Total & $\mathbf{4 0}$ & $\mathbf{1 0 0 \%}$ & $\mathbf{2 5}$ & $\mathbf{1 0 0 \%}$ \\
\hline Mean gestation \pm SD & $\mathbf{3 2 . 3 8} \pm \mathbf{2 . 5 3}$ & $\mathbf{2 9 . 4 8} \pm \mathbf{2 . 5 0}$ \\
\hline
\end{tabular}

- Mean age in the study group and control group was $26.6 \pm 4.48$ and $25.0 \pm 2.79$ years respectively was comparable.

- $52 \%$ patients in each study and control group were primigravida.

- Mean gestation in study group i.e. $32.38 \pm 2.53$ weeks and $29.48 \pm 2.50$ in control group was comparable.

Table 2a: Distribution in study group (preeclampsia according to severity)

\begin{tabular}{|l|c|c|}
\hline Preeclampsia & No. & \%age \\
\hline Non-Severe Preeclampsia & 23 & $57.5 \%$ \\
\hline Severe Preeclampsia & 17 & $42.5 \%$ \\
\hline Total & $\mathbf{4 0}$ & $\mathbf{1 0 0 \%}$ \\
\hline
\end{tabular}

B Comparison of Systolic / Diastolic Blood Pressure in Study and Control Group

\begin{tabular}{|c|l|l|l|l|}
\hline & Systolic Blood Pressure $(\mathbf{m m}$ Hg) & \multicolumn{2}{|c|}{ Diastolic Blood Pressure (mm Hg) } \\
\hline & Mean \pm SD & SEM & Mean \pm SD & SEM \\
\hline Study Group & $156.00 \pm 14.10$ & 2.230 & $105.25 \pm 10.55$ & 1.668 \\
\hline Control Group & $114 \pm 5.83$ & 1.166 & $76.00 \pm 5.53$ & 1.108 \\
\hline$p$ & \multicolumn{2}{|c|}{$<0.001$} & \multicolumn{2}{c|}{ HS } \\
\hline HS & \multicolumn{2}{c|}{} \\
\hline
\end{tabular}

2a 17 cases $(42.5 \%)$ had severe preeclampsia while $57.5 \%$ were non-severe preeclampsia in study group.

2b Difference between mean systolic and diastolic blood pressure in the two groups was highly significant. $\mathrm{p}$ $<0.001$ 
Table 3 : Comparison of Laboratory Tests in Study \& Control groups

\begin{tabular}{|l|l|l|l|l|}
\hline \multicolumn{1}{|c|}{ Laboratory Test } & \multicolumn{1}{|c|}{$\begin{array}{c}\text { Study Group } \\
\text { Mean } \pm \text { SD }\end{array}$} & \multicolumn{1}{|c|}{$\begin{array}{c}\text { Control Group } \\
\text { Mean } \pm \text { SD }\end{array}$} & P & S \\
\hline Blood urea mg \% & $25.25 \pm 3.46$ & $24.32 \pm 2.82$ & 0.238 & NS \\
\hline Serum Creatnine mg \% & $1.05 \pm 0.27$ & $0.72 \pm 0.15$ & $<0.001$ & HS \\
\hline Serum Uric acid mg \% & $5.56 \pm 1.25$ & $3.92 \pm 0.64$ & $<0.001$ & HS \\
\hline Platelet Count (mm3) & $211800 \pm 84821$ & $32800 \pm 48201$ & $<0.001$ & HS \\
\hline SGOT (IU/L) & $74.60 \pm 56.40$ & $21.56 \pm 6.65$ & $<0.001$ & HS \\
\hline SGPT (IU/L) & $77.95 \pm 67.40$ & $24.28 \pm 9.15$ & $<0.001$ & HS \\
\hline
\end{tabular}

Serum creatnine /uric acid / SGOT/PT were significantly raised and platelet count decreased in study group compared to control group.

Table 4: Comparison of Hemoglobin /Fasting plasma glucose and Insulin levels

\begin{tabular}{|c|c|c|c|c|c|}
\hline & \multicolumn{2}{|c|}{ Study Group (Preeclampsia) } & Control Group & $\mathbf{p}$ & $\mathbf{S}$ \\
\hline Mean $\mathrm{Hb}(\mathrm{gm} \%)$ & \multicolumn{2}{|c|}{$9.77 \pm 0.71$} & $10.04 \pm 0.82$ & 0.172 & NS \\
\hline $\begin{array}{l}\text { Mean Fasting Plasma } \\
\text { Glucose }(\mathrm{mg} \%)\end{array}$ & \multicolumn{2}{|c|}{$79.38 \pm 3.92$} & $78.25 \pm 5.98$ & 0.359 & NS \\
\hline \multirow{3}{*}{$\begin{array}{l}\text { Mean Fasting Plasma } \\
\text { Insulin }(\mu 1 \mathrm{U} / \mathrm{m})\end{array}$} & \multicolumn{2}{|c|}{$53.31 \pm 22.57$} & $16.35 \pm 5.79$ & $<0.001$ & HS \\
\hline & Severe & Non-severe & & & \\
\hline & $72.33 \pm 19.16$ & $39.25 \pm 12.22$ & & $<0.001$ & $\mathrm{HS}$ \\
\hline
\end{tabular}

- Hemoglobin level and Fasting Plasma Glucose levels were comparable in study and control group.

- Mean fasting plasma insulin level in study group was $53.31 \mu \mathrm{lU} / \mathrm{ml}$ compared to $16.35 \mu \mathrm{IU} / \mathrm{ml}$ in control group. Difference in two groups is statistically highly significant. $(\mathrm{p}<0.001)$

- Difference in mean fasting plasma insulin levels between severe and non-severe preeclampisa was also highly significant $(\mathrm{p}<0.001)$

Table 5: Comparison of Homa-IR Index (Insulin Resistance) in Groups

\begin{tabular}{|c|l|l|l|l|l|l|}
\hline Insulin Resistance IR & \multicolumn{1}{|l|}{ Study Group } & \multicolumn{1}{|c|}{ Control Group } & P & S \\
\cline { 2 - 6 } & Mean \pm SD & SEM & Mean \pm SD & SEM & & \\
\hline \multirow{4}{*}{ HOMA-IR-Index } & $10.33 \pm 4.10$ & 0.648 & $3.04 \pm 1.01$ & 0.203 & $<0.001$ & HS \\
\cline { 2 - 7 } & Severe Preeclampsia & \multicolumn{2}{|c|}{ Control Group } & & \\
\cline { 2 - 7 } & $13.83 \pm 3.23$ & 0.783 & $3.04 \pm 1.01$ & 0.203 & $<0.001$ & HS \\
\cline { 2 - 7 } & \multicolumn{2}{|c|}{ Severe Preeclampsia } & Non-Severe Preeclampsia & & \\
\cline { 2 - 7 } & $13.83 \pm 3.23$ & 0.783 & $7.74 \pm 2.37$ & 0.473 & $<0.001$ & HS \\
\hline
\end{tabular}

- Mean value of HOMA IR Index in study group was 10.33 compared to 3.04 in control group (p <0.001)

- Mean value of HOMA IR Index in Severe preeclampsia was 13.83 33.23 compared to 3.04 in control group (p $<0.001)$

- Mean value of HOMA IR Index in Severe preeclampsia was $13.83 \pm 3.23$ compared to 7.74 \pm 2.37 in Nonsevere preeclmapsia group $(\mathrm{p}<0.001)$

Table 6: Comparison of Fasting Plasma Insulin level in preeclampsia and Normotensive Pregnant Women in different studies

\begin{tabular}{|l|l|l|c|}
\hline \multirow{2}{*}{} & Authors & \multicolumn{2}{|c|}{ Comparison of Fasting Plasma Insulin levels } \\
\cline { 3 - 4 } & & \multicolumn{1}{|c|}{ P } \\
\hline 1. & Xu et al 2000 & S & HS \\
\hline 2. & Paradise et al 2006 ${ }^{[15]}$ & 0.018 & $\mathrm{~S}$ \\
\hline 3. & Giourad et al 2007 $^{[16]}$ & $<0.004$ & $\mathrm{HS}$ \\
\hline 4. & Hauth et al 2001 $^{[17]}$ & $<0.001$ & $\mathrm{HS}$ \\
\hline 5. & Present Study 2013 & $<0.001$ & HS \\
\hline
\end{tabular}

Table 7: Comparison Of Lipid Profile In Study Group (Severe /Non-Severe Preeclampsia ) And Control Group

\begin{tabular}{|c|c|c|c|c|}
\hline 7 (a) & $\begin{array}{l}\text { Study Group Non-severe } \\
\text { Preeclampsia }(\text { Mean } \pm \text { SD) }\end{array}$ & $\begin{array}{l}\text { Control Group } \\
(\text { Mean } \pm \text { SD) }\end{array}$ & $\mathbf{p}$ & $\mathbf{s}$ \\
\hline S. Cholesterol (mg/dl) & $233.39 \pm 40.51$ & $170.92 \pm 40.57$ & $<0.001$ & HS \\
\hline S. Triglycerides $(\mathrm{mg} / \mathrm{dl})$ & $223.83 \pm 72.23$ & $133.36 \pm 51.81$ & $<0.001$ & HS \\
\hline $\mathrm{HDL}(\mathrm{mg} / \mathrm{dl})$ & $46.09 \pm 3.96$ & $41.52 \pm 4.49$ & $<0.001$ & HS \\
\hline $\mathrm{LDL}(\mathrm{mg} / \mathrm{dl})$ & $148.91 \pm 35.58$ & $102.68 \pm 31.95$ & $<0.001$ & HS \\
\hline $\operatorname{VLDL}(\mathrm{mg} / \mathrm{dl})$ & $44.13 \pm 13.87$ & $26.64 \pm 10.44$ & $<0.001$ & HS \\
\hline $7 \mathrm{~b}$ & Severe Preeclampsia & & & \\
\hline S. Cholesterol $(\mathrm{mg} / \mathrm{dl})$ & $310.53 \pm 39.22$ & $170.92 \pm 40.57$ & $<0.001$ & HS \\
\hline S. Triglycerides $(\mathrm{mg} / \mathrm{dl})$ & $272.71 \pm 53.69$ & $133.36 \pm 51.81$ & $<0.001$ & HS \\
\hline $\mathrm{HDL}(\mathrm{mg} / \mathrm{dl})$ & $48.65 \pm 3.14$ & $41.52 \pm 4.49$ & $<0.001$ & HS \\
\hline $\mathrm{LDL}(\mathrm{mg} / \mathrm{dl})$ & $207.47 \pm 41.69$ & $102.68 \pm 31.95$ & $<0.001$ & HS \\
\hline VLDL $(\mathrm{mg} / \mathrm{dl})$ & $54.18 \pm 10.24$ & $26.64 \pm 10.44$ & $<0.001$ & HS \\
\hline
\end{tabular}

Lipid Profile - Total serum cholesterol / Triglycerides/ HDL / LDL/ VLDL were significantly higher in study group (Severe as well as Non-severe preeclampsia) compared to Normotensive pregnant women $(\mathrm{p}<0.001)$ 